\title{
Rapid Synthesis of Dittmarite by Microwave-Assisted Hydrothermal Method
}

\author{
Lai zhenyu, ${ }^{1,2}$ Qian Jueshi, ${ }^{2}$ Lu Zhongyuan, ${ }^{1}$ Li Qian, ${ }^{1}$ and Zou Qiulin' \\ ${ }^{1}$ School of Materials Science and Engineering, Southwest University of Science and Technology, Sichuan, Mianyang 621010, China \\ ${ }^{2}$ School of Materials Science and Engineering, Chongqing University, Chongqing 400030, China
}

Correspondence should be addressed to Lai zhenyu, laizhenyu@swust.edu.cn

Received 9 April 2012; Revised 29 June 2012; Accepted 29 June 2012

Academic Editor: Markku Leskela

Copyright ( 2012 Lai zhenyu et al. This is an open access article distributed under the Creative Commons Attribution License, which permits unrestricted use, distribution, and reproduction in any medium, provided the original work is properly cited.

\begin{abstract}
Dittmarite was obtained using $\mathrm{MgO}$ and $\left(\mathrm{NH}_{4}\right)_{2} \mathrm{HPO}_{4}$ as raw materials via microwave-assisted hydrothermal method for 3 min at $120^{\circ} \mathrm{C}$. The resulting samples were investigated by X-ray powder diffraction, scanning electron microscopy, Fourier transform infrared spectroscopy, and thermogravimetry-differential thermal analysis. The results indicate that dittmarite can be rapidly synthesized by microwave-assisted hydrothermal method. With higher temperature and longer reaction time, highly crystallized dittmarite can be obtained. Pure dittmarite can be synthesized for $3 \mathrm{~min}$ at $120^{\circ} \mathrm{C}$, which is faster than with the use of any other reported methods.
\end{abstract}

\section{Introduction}

Dittmarite was first discovered at Skipton Caves by MacIvor in Australia [1]. The mineral has gained interest because of its strongly defined layered crystal structures. Many researchers have studied a series of compounds, $\mathrm{M}_{\mathrm{I}} \mathrm{M}_{\mathrm{II}} \mathrm{PO}_{4} \cdot \mathrm{H}_{2} \mathrm{O}\left(\mathrm{M}_{\mathrm{I}}\right.$ $\left.=\mathrm{NH}_{4}, \mathrm{~K} ; \mathrm{M}_{\mathrm{II}}=\mathrm{Mn}, \mathrm{Fe}, \mathrm{Co}, \mathrm{Ni}\right)$, related to dittmarite for their synthesis [2] and application in shape-selective redox catalysts, ionic exchange, ionic conductivity, magnetic properties, and so on [3-6].

The present study focuses on the rapid synthesis of pure dittmarite via microwave-assisted hydrothermal method. $\mathrm{MgO}$ was used as the source of magnesium and $\left(\mathrm{NH}_{4}\right)_{2} \mathrm{HPO}_{4}$ was used as the source of phosphate and ammonium. The phases of the samples were identified by X-ray powder diffraction (XRD). The microstructure, infrared spectrum, and thermal properties of the samples were measured by scanning electron microscopy (SEM), Fourier transform infrared spectroscopy, and thermogravimetry-differential thermal analysis (TG-DTA), respectively.

\section{Experiment}

The $\mathrm{MgNH}_{4} \mathrm{PO}_{4} \cdot \mathrm{H}_{2} \mathrm{O}$ compound was prepared by a microwave-assisted hydrothermal method using Ethos
A (Milestone, Italy). Analytical reagents $\mathrm{MgO}$ and $\left(\mathrm{NH}_{4}\right)_{2} \mathrm{HPO}_{4}$ were added in a half-filled Teflon container, keeping the solution $\mathrm{pH}$ by adding $\mathrm{KOH}$ at approximately 8. The solutions were microwaved for 3, 5, and $10 \mathrm{~min}$ at 50,80 , and $120^{\circ} \mathrm{C}$. The resulting precipitate was separated by filtration, washed with deionized water and ethanol, and then dried for $24 \mathrm{~h}$ at $80^{\circ} \mathrm{C}$.

The as-prepared samples were identified by XRD analysis on $\mathrm{D} / \mathrm{max}-\mathrm{RB}$ diffractometer (Rigaku, Japan) using $\mathrm{CuK} \alpha$ radiation $(\lambda=1.5418 \AA)$ in the $2 \theta$ range of $5^{\circ}$ to $70^{\circ}$. Differential thermal analysis and thermogravimetry were traced using STA 449 C Jupiter (NETZSCH, Germany). Using TM-1000 (HITACHI, Japan), the SEM images of the samples were visualized. The infrared absorption spectrum of the sample was measured by a Thermo Scientific Nicolet 380 FT-IR spectrometer (Thermo Fisher Scientific, USA).

\section{Results and Discussion}

Figure 1 shows the powder XRD patterns of the synthetic samples with various temperatures and reaction times. Figure 1(a) illustrates the XRD patterns of samples prepared under $50^{\circ} \mathrm{C}$ for 3,5 , and $10 \mathrm{~min}$. The main phase is $\mathrm{MgO}$, but many reflections with lower intensity which represent 


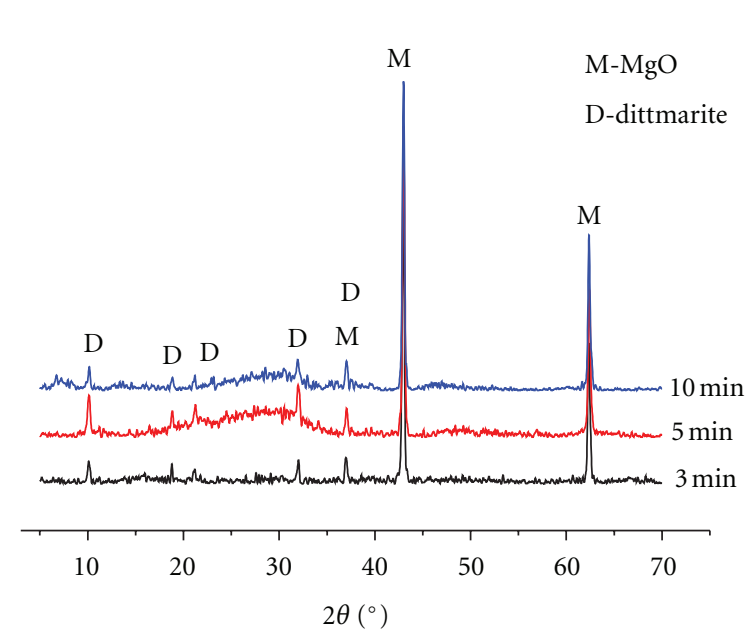

(a) $50^{\circ} \mathrm{C}$

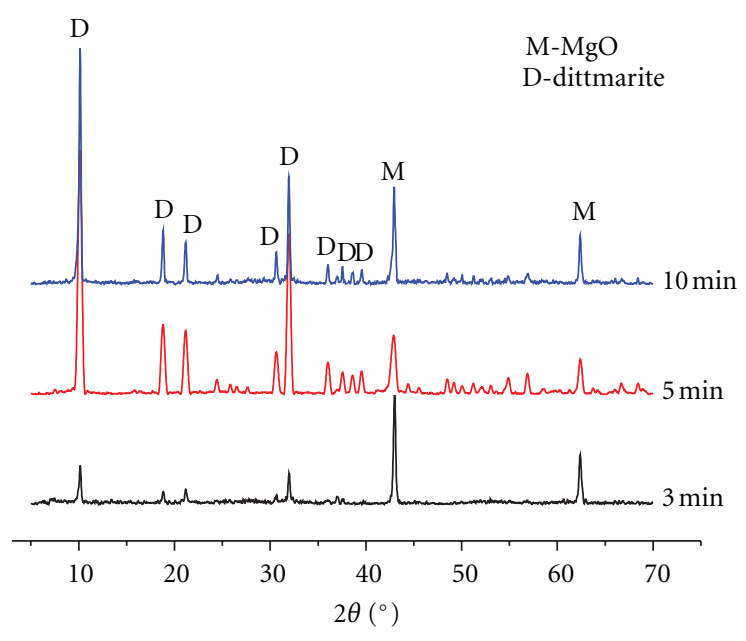

(b) $80^{\circ} \mathrm{C}$

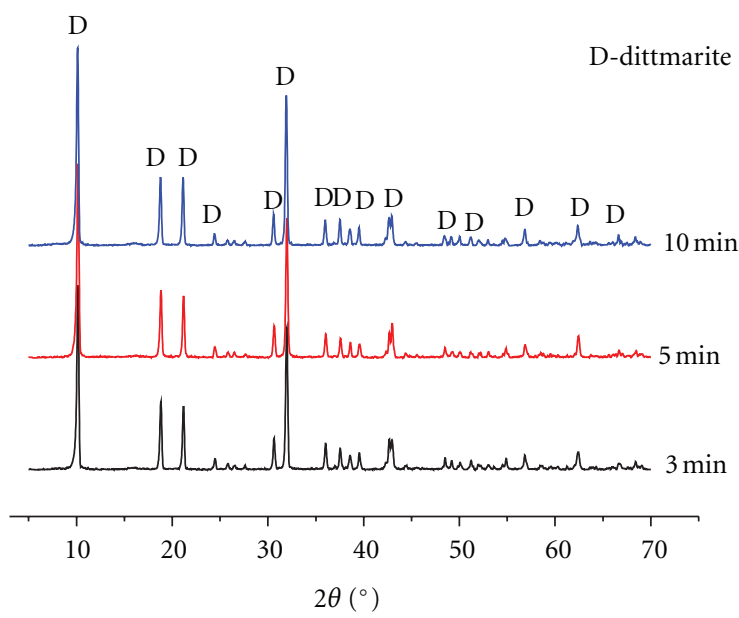

(c) $120^{\circ} \mathrm{C}$

FIGURE 1: XRD patterns of the samples.

dittmarite can also be found. In Figure 1(b), dittmarite and $\mathrm{MgO}$ still coexist in the samples, but the peak intensity of dittmarite increases with longer reaction times. Meanwhile, the peak intensity of $\mathrm{MgO}$ decreases with longer reaction times. The XRD patterns shown in Figure 1(c) match closely with the published pattern for dittmarite (JCPDF 36-1491). Thus, they are considered as single-phase materials. This result indicates that dittmarite can be easily synthesized by microwave-assisted hydrothermal method under $120^{\circ} \mathrm{C}$ within a 3 min reaction time.

The SEM micrograph of dittmarite is shown in Figure 2. The sample is mainly composed of plate-like dittmarite. The particles of dittmarite are in agglomeration state with a flower-like shape, the result is similar with the SEM morphgraph of dittmarite-type compound $\mathrm{KMnPO}_{4} \cdot \mathrm{H}_{2} \mathrm{O}$ prepared by Koleva et al. [7].

The FT-IR absorption spectrum for dittmarite is shown in Figure 3. The phosphate ion vibrations are at about $1,061,979$, and $576 \mathrm{~cm}^{-1}$. All the bands between 3250 and $2400 \mathrm{~cm}^{-1}$ belong to the $\mathrm{NH}_{4}{ }^{+}$stretching modes The bands at 3500 and $1641 \mathrm{~cm}^{-1}$ appear as a result of the stretching and

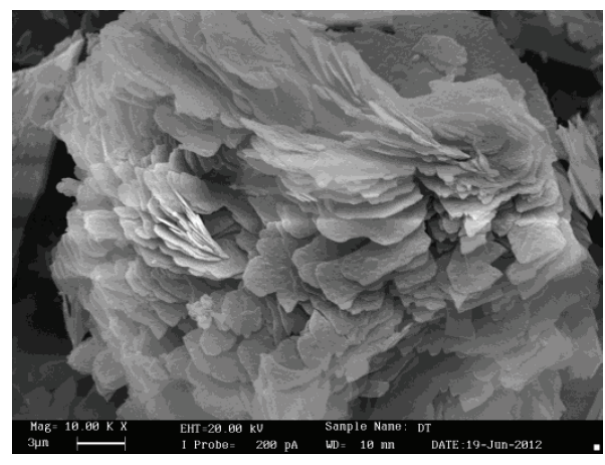

FIGURE 2: SEM morphgraph of dittmarite.

bending $\mathrm{H}_{2} \mathrm{O}$ vibrations, respectively, and around $1470 \mathrm{~cm}^{-1}$ belong to the $\mathrm{NH}_{4}{ }^{+}$bending vibrations. The $\mathrm{H}_{2} \mathrm{O}$ bending mode band is expected to appear at $\sim 1500 \mathrm{~cm}^{-1}$ whereas the vibration at $633 \mathrm{~cm}^{-1}$ represents the $\mathrm{Mg}-\mathrm{O}$ bond. This spectrum is in accordance with previous studies [8-10]. 


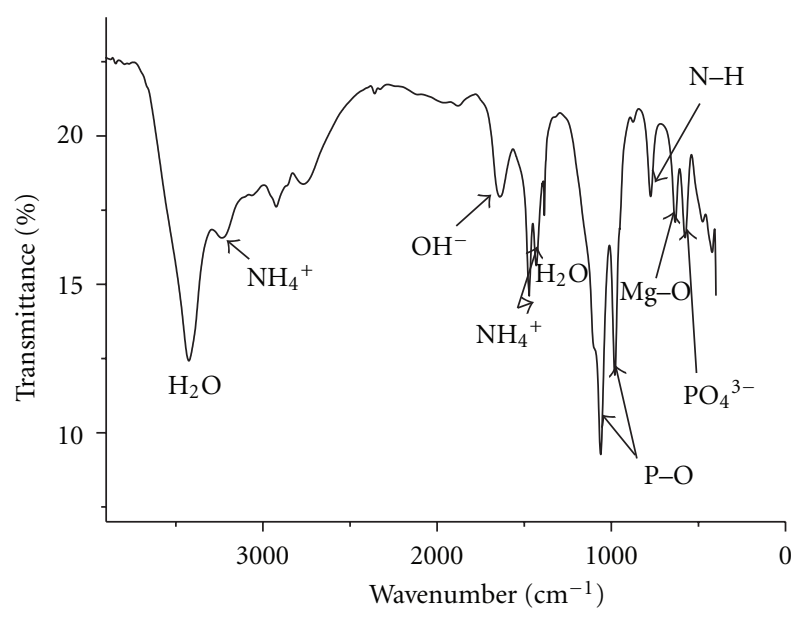

FIGURE 3: FT-IR spectrum of the as-prepared dittmarite.

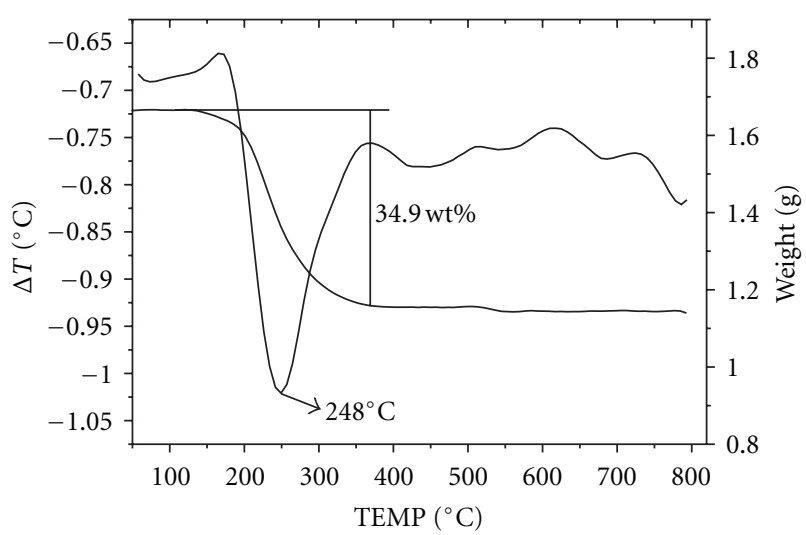

FIGURE 4: TG-DTA curves for the as-prepared dittmarite.

The TG and DTA curves of the obtained dittmarite at a rate of $10^{\circ} \mathrm{C} / \mathrm{min}$ from ambient temperature to $800^{\circ} \mathrm{C}$ are presented in Figure 4 . The thermal decomposition study shows the endothermic steps in the temperature range from $165^{\circ} \mathrm{C}$ to $370^{\circ} \mathrm{C}$, and the experiment value is $34.9 \mathrm{wt} \%$, which corresponds to the mass loss of water and ammonia molecules present in the structure.

Based on the above results, the formation mechanism of dittmarite can be discussed as follows. Due to heating by microwave irradiation, the samples result in homogeneous nucleation within a very short time and the nucleation and crystal growth occur simultaneously. For the past few years, many researchers have posited that the kinetics of material synthesis may be significantly accelerated using microwaveassisted hydrothermal methods [11-14]. In the current study, the rapid synthesis of dittmarite by microwave-assisted hydrothermal methods was found to have the potential for saving energy and cost of production.

\section{Conclusions}

In the current paper, dittmarite was rapidly synthesized by microwave-assisted hydrothermal methods at $120^{\circ} \mathrm{C}$ for
3 min using $\mathrm{MgO}$ and $\left(\mathrm{NH}_{4}\right)_{2} \mathrm{HPO}_{4}$ as raw materials. Microwave irradiation can significantly accelerate the reaction. The anticipated materials can be prepared at lower temperature and shorter reaction time using microwave heating.

\section{Acknowledgments}

Financial support from the National Natural Science Foundation of China (10976023), the Key Subject Laboratory of National Defense for Radioactive Waste and Environmental Security (08ZXNP05), the Key Project of Southwest University of Science and Technology (06ZX2148), and the Opening Project of Key Laboratory for Advanced Building Materials of Sichuan Province (07XZJ002) is gratefully acknowledged.

\section{References}

[1] B. P. Onac and P. Forti, "Minerogenetic mechanisms occurring in the cave environment: an overview," International Journal of Speleology, vol. 40, pp. 78-98, 2011.

[2] H. Basset and W. Bedwell, "Studies of phosphates. Part I. Ammonium magnesium phosphate and related compounds," Journal of the Chemical Society, pp. 854-871, 1933.

[3] A. Pujana, J. L. Pizarro, L. Lezama, A. Goñi, M. I. Arriortua, and T. Rojo, "Synthesis, crystal structure, and magnetic properties of $\mathrm{NH}_{4} \mathrm{CuPO}_{4} \cdot \mathrm{H}_{2} \mathrm{O}$," Journal of Materials Chemistry, vol. 8, no. 4, pp. 1055-1060, 1998.

[4] Y. Ding, D. J. Jones, P. M. Torres, and J. Roziere, "Twodimensional nanocomposites: alternating inorganic-organic polymer layers in zirconium phosphate," Chemistry of Materials, vol. 7, no. 3, pp. 562-571, 1995.

[5] A. Pujana, J. L. Pizarro, L. Lezama, A. Goni, M. I. Arriortua, and T. Rojo, "Hydrothermal synthesis, structural, spectroscopic and magnetic studies of the $\mathrm{NH}_{4} \mathrm{Mn}\left(\mathrm{AsO}_{4}\right) \cdot \mathrm{H}_{2} \mathrm{O}$ arsenate type dittmarite," Materials Research Bulletin, vol. 34, no. $10-11$, pp. $1545-1555,1999$.

[6] V. G. Koleva, "Metal-water interactions and hydrogen bonding in dittmarite-type compounds $\mathrm{M}^{\prime} \mathrm{M}^{\prime \prime} \mathrm{PO}_{4} \cdot \mathrm{H}_{2} \mathrm{O}\left(\mathrm{M}^{\prime}=\mathrm{K}^{+}\right.$, $\left.\mathrm{NH}_{4}{ }^{+} ; \mathrm{M}^{\prime \prime}=\mathrm{Mn}^{2+}, \mathrm{Co}^{2+}, \mathrm{Ni}^{2+}\right)$ : correlations of IR spectroscopic and structural data," Spectrochimica Acta-Part A, vol. 62, no. 4-5, pp. 1196-1202, 2005.

[7] V. Koleva, E. Zhecheva, and R. Stoyanova, "Facile synthesis of $\mathrm{LiMnPO}_{4}$ olivines with a plate-like morphology from a dittmarite-type $\mathrm{KMnPO}_{4} \cdot \mathrm{H}_{2} \mathrm{O}$ precursor," Dalton Transactions, vol. 40, no. 28, pp. 7385-7394, 2011.

[8] A. K. Sarkar, "Hydration/dehydration characteristics of struvite and dittmarite pertaining to magnesium ammonium phosphate cement systems," Journal of Materials Science, vol. 26, pp. 2514-2518, 1991.

[9] B. Šoptrajanov, V. Stefov, I. Kuzmanovski, G. Jovanovski, H. D. Lutz, and B. Engelen, "Very low $\mathrm{H}-\mathrm{O}-\mathrm{H}$ bending frequencies. IV. Fourier transform infrared spectra of synthetic dittmarite," Journal of Molecular Structure, vol. 613, no. 1-3, pp. 7-14, 2002.

[10] V. G. Koleva, "Vibrational behavior of the phosphates ions in dittmarite-type compounds $\mathrm{M}^{\prime} \mathrm{M}^{\prime \prime} \mathrm{PO}_{4} \cdot \mathrm{H}_{2} \mathrm{O}\left(\mathrm{M}^{\prime}=\mathrm{K}^{+}, \mathrm{NH}_{4}{ }^{+}\right.$; $\left.\mathrm{M}^{\prime \prime}=\mathrm{Mn}^{2+}, \mathrm{Co}^{2+}, \mathrm{Ni}^{2+}\right)$," Spectrochimica Acta-Part A, vol. 66, no. 2, pp. 413-418, 2007.

[11] S. Ifrah, A. Kaddouri, P. Gelin, and D. Leonard, "Conventional hydrothermal process versus microwave-assisted hydrothermal synthesis of $\mathrm{La}_{1-x} \mathrm{Ag}_{x} \mathrm{MnO}_{3+\delta}(x=0,0.2)$ perovskites used 
in methane combustion," Comptes Rendus Chimie, vol. 10, no. 12, pp. 1216-1226, 2007.

[12] Y. Hu, C. Liu, Y. Zhang, N. Ren, and Y. Tang, "Microwaveassisted hydrothermal synthesis of nanozeolites with controllable size," Microporous and Mesoporous Materials, vol. 119, no. 1-3, pp. 306-314, 2009.

[13] Y.-Z. Wang and Y. Fu, "Microwave-hydrothermal synthesis and characterization of hydroxyapatite nanocrystallites," Materials Letters, vol. 65, no. 23-24, pp. 3388-3390, 2011.

[14] L. Zhenyu, X. Guangliang, and Z. Yalin, "Microwave assisted low temperature synthesis of MnZn ferrite nanoparticles," Nanoscale Research Letters, vol. 2, no. 1, pp. 40-43, 2007. 

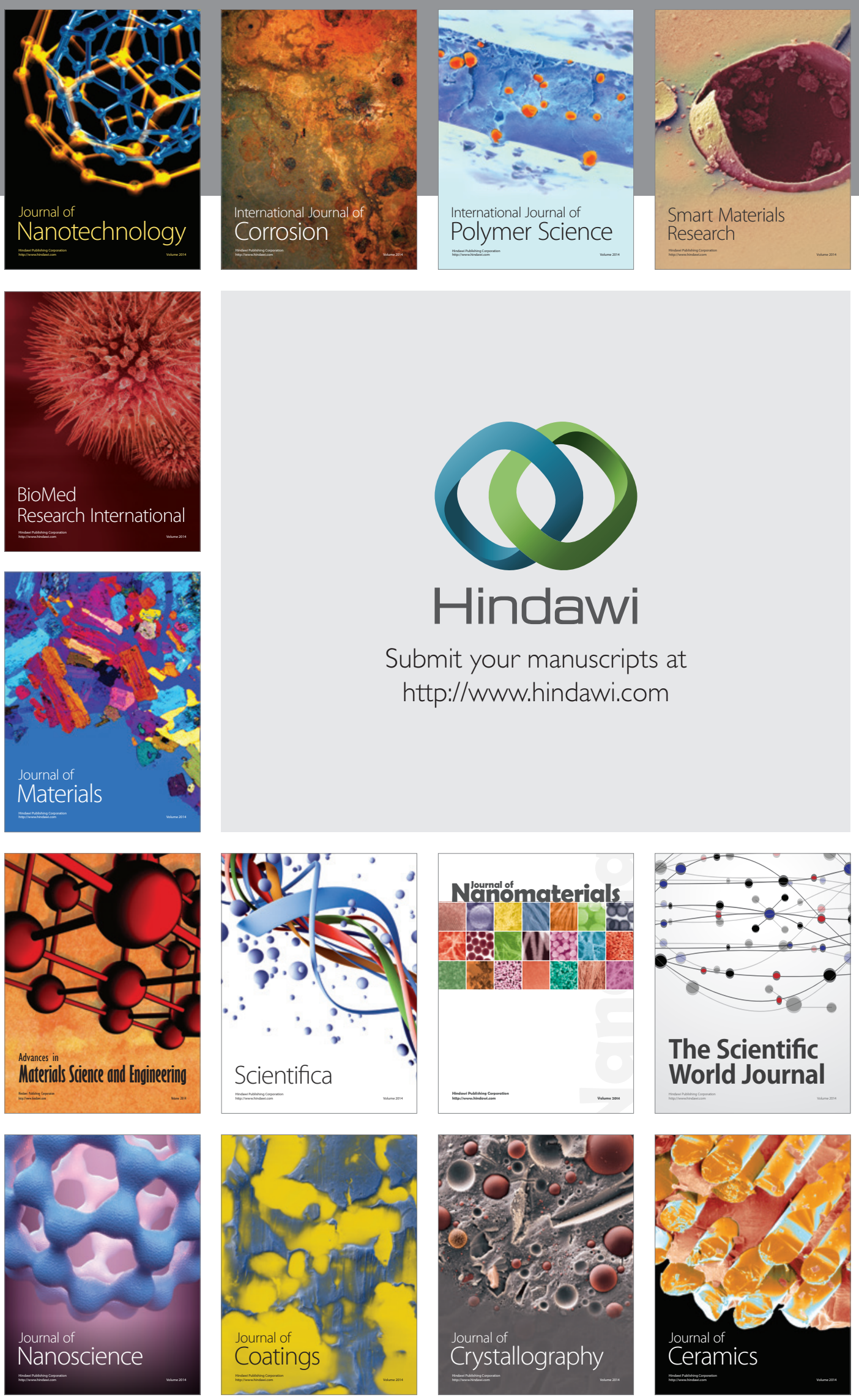

The Scientific World Journal

Submit your manuscripts at

http://www.hindawi.com

\section{World Journal}

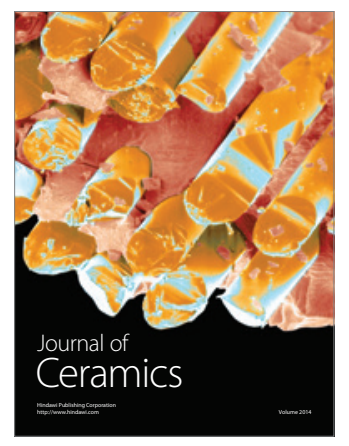

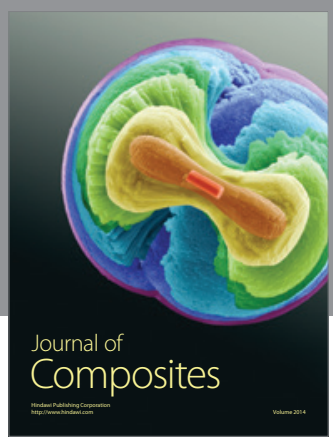
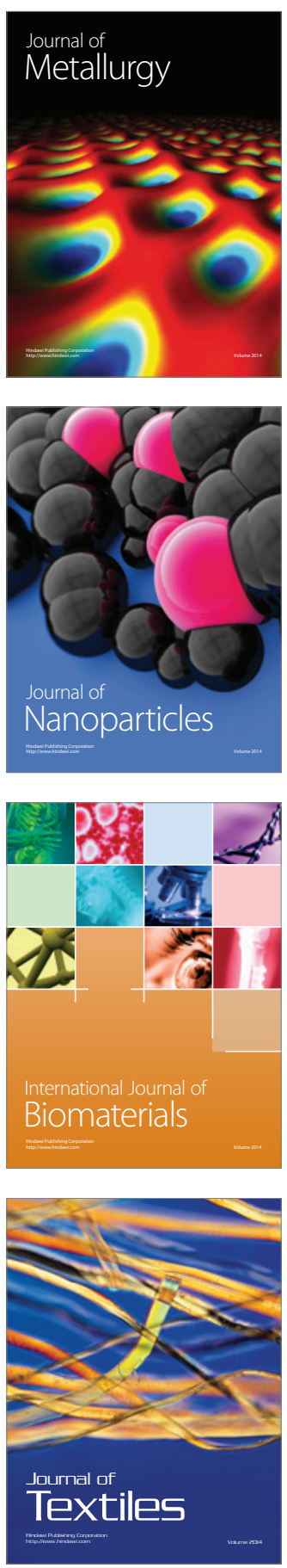